\title{
Studying the non-thermal plasma jet characteristics and application on bacterial decontamination
}

\author{
Ali F. Al-rawaf ${ }^{1} \cdot$ Fadhil Khaddam Fuliful $^{1} \cdot$ Mohammed K. Khalaf $^{2} \cdot$ Husham. K. Oudah $^{3}$
}

Received: 14 November 2017 / Accepted: 9 April 2018/Published online: 25 April 2018

(C) The Author(s) 2018

\begin{abstract}
Non-thermal atmospheric-pressure plasma jet represents an excellent approach for the decontamination of bacteria. In this paper, we want to improve and characterize a non-thermal plasma jet to employ it in processes of sterilization. The electrical characteristics was studied to describe the discharge of the plasma jet and the development of plasma plume has been characterized as a function of helium flow rate. Optical emission spectroscopy was employed to detect the active species inside the plasma plume. The inactivation efficiency of non-thermal plasma jet was evaluated against Staphylococcus aureus bacteria by measuring the diameter of inhibition zone and the number of surviving cells. The results presented that the plasma plume temperature was lower than $34^{\circ} \mathrm{C}$ at a flow rate of $4 \mathrm{slm}$, which will not cause damage to living tissues. The diameter of inhibition zone is directly extended with increased exposure time. We confirmed that the inactivation mechanism was unaffected by UV irradiation. In addition, we concluded that the major reasons for the inactivation process of bacteria is because of the action of the reactive oxygen and nitrogen species which formed from ambient air, while the charged particles played a minor role in the inactivation process.
\end{abstract}

Keywords DBD plasma jet - Optical emission spectroscopy $\cdot$ Staphylococcus aureus - Decontamination

\section{Introduction}

Recently, non-thermal atmospheric pressure plasma has attracted considerable attention in biomedical applications due to its simplicity and efficiency [1]. Conventionally, UV emissions, heat (more than $120{ }^{\circ} \mathrm{C}$ ), ethanol and strong chemicals [2,3] are effective sterilizing methods for inactivation of microorganisms. These methods have recently raised general disagreements about their environmental effects. Therefore, new methods of sterilization should be sought which have some advantages such as safety, convenience and lack of residual toxicity [4]. Nonthermal plasma is an alternative to conventional

Ali F. Al-rawaf

ali.physics@ymail.com

1 Department of Physics, College of Science, University of Kerbala, Karbala, Iraq

2 Center of Applied Physics, Ministry of Science and Technology, Baghdad, Iraq

3 Center of Environment and Water, Ministry of Science and Technology, Baghdad, Iraq sterilization methods [5] and is considered as a new sterilization technique in the conservation of materials from bacteria [4]. This method has several advantages such as the possibility of inactivating the bacteria at low temperatures (near room temperature), being economical, absence of residual toxicity, and appropriateness for applications when product conservation is required $[6,7]$. They have become very attractive for biomedical applications such as bacteria inactivation [8,9], wound healing [10], decontamination of medical equipment [11], and blood coagulation [12]. The non-thermal plasma consists of neutral gas atoms or molecules, ions, electrons and reactive species [13]. It is reported that the reactive species and excited neutrals in the non-thermal plasma are responsible for the microorganism inactivation since they are able to modify the DNAs, proteins, and cell membranes [14, 15].

Nishime et al. [16] evaluated the sterilizing efficacy of a DBD non-thermal helium plasma jet toward Gram-positive and Gram-negative bacteria, and demonstrated that the sterilizing efficacy depends critically on the active species such as ozone. Maisch et al. [17] evaluated the antimicrobial effects and the mechanism of cold atmospheric 
plasma treatment on MRSA, Staphylococcus aureus and $E$. coli bacteria and showed that the bacteria inactivation increased with longer treatment time.

The fundamental objective of this work is to develop an understanding of the effects of non-thermal plasma jet on bacterial decontamination. Although there have been numerous studies that deal with decontamination of bacteria using atmospheric pressure plasma jet (APPJ), less attention has been paid to using double-ring electrodes in enhancing the performance of plasma jets system, which can lead to more efficient sterilization of bacteria. In addition, the efficiency of sterilization has been shown clearly when treating with plasma jets in spite of the lower applied voltage.

\section{Experimental part}

\section{Experimental facility}

The plasma jet used in this study is a dielectric barrier discharge (DBD) type APPJ. The schematic diagram of the DBD plasma jet is shown in Fig. 1. It consists of a Pyrex tube representing a dielectric barrier discharge. The length of the tube was $95 \mathrm{~mm}$ with wall thickness of $0.925 \mathrm{~mm}$, while the internal and external diameters of the tube were 2 $\mathrm{mm}$ and $3.85 \mathrm{~mm}$, respectively. Helium gas with commercial grade of $99.998 \%$ was fed at the upper part of the Pyrex tube and the flow rate was controlled by flow meters 11420 (Mathesen, USA) and needle valve 28801 B2 (Leybold, Germany). The DBD plasma jet device was based on a double-ring structure with two aluminum ring electrodes covering the external Pyrex tube. The thickness and width of the aluminum ring were 0.1 and $12 \mathrm{~mm}$, respectively. The distance between two electrodes was 13 $\mathrm{mm}$ and the distance between the downstream electrode and the nozzle of the Pyrex tube was $4 \mathrm{~mm}$. The upstream

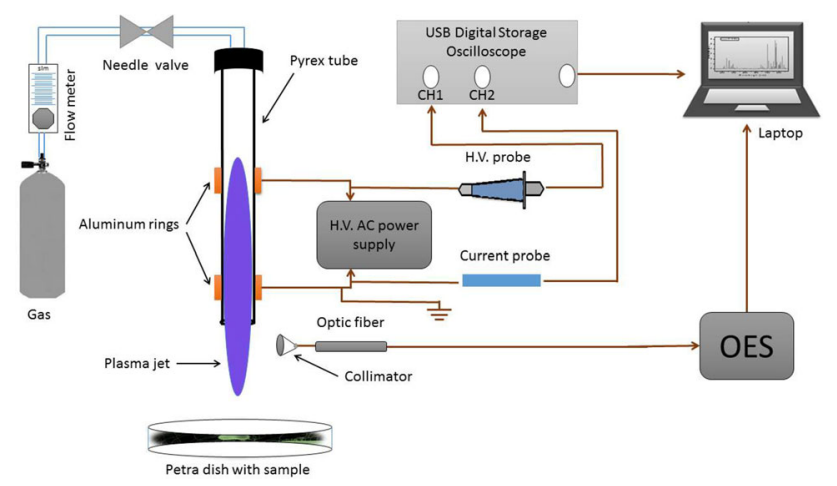

Fig. 1 Schematic representation of the DBD plasma jet system electrode was connected to a power supply and the downstream electrode was grounded.

\section{Instrumentation for plasma characterization}

The BDB plasma jet was driven by a homemade highvoltage AC power supply under fixed frequency of $12 \mathrm{kHz}$ with variable voltage from 0 to $7.5 \mathrm{kV}_{p-p}$. The electrical properties were measured by a high-voltage probe $\mathrm{P} 6015 \mathrm{~A}$ (Tektronix, USA) and a current probe AT-C202 (Generic, China). The waveforms of the applied voltage and discharge current were recorded using PC USB oscilloscope 6022BE (Hantek, China) with a $20 \mathrm{MHz}$ bandwidth and a $48 \mathrm{MS} / \mathrm{s}$ sampling rate. The plasma gas temperature was measured by alcohol thermometer using different flow rates at a distance of $15 \mathrm{~mm}$ from the nozzle of the Pyrex tube. The emission spectra of the DBD plasma jet was determined by ultraviolet visible (UV-Vis) spectrometer device SV2100 (Kmac, Korea) with wavelength range from 200 to $1100 \mathrm{~nm}$. The spectrometer device was connected with an optical fiber cable M92L01 (Thorlabs, USA) to record the spectral emissions. To avoid the dispersion of plasma radiation, a collimator was used to assemble the radiation emitted from the plasma. The collimator was located at $20 \mathrm{~mm}$ from the edge of the Pyrex tube (axial direction) and $20 \mathrm{~mm}$ from the wall of the Pyrex tube (radical direction).

\section{Sample preparation}

A bacterial suspension was prepared for $S$. aureus bacteria with specific concentrations. This concentrations were measured by UV-Vis spectrophotometer device SP-3000 Plus (Optima, Japan) at $625 \mathrm{~nm}$ and was 0.402, which is equivalent to $6.5 \times 10^{8}$ bacteria cell-forming units per $\mathrm{ml}$ $(\mathrm{CFU} / \mathrm{ml})$. After the suspension was prepared, $0.1 \mathrm{ml}$ of this suspension, containing $6.5 \times 10^{8} \mathrm{CFU} / \mathrm{ml}$ bacteria, was spread on the nutrient agar via the spreading method by a sterile swab in a standard Petri dish. The dishes were stored in an aseptic location to dry for $10 \mathrm{~min}$ and then exposed to the plasma jet; see Fig. 2.

\section{Treatment conditions}

For all treatments, the DBD plasma jet was operated under a frequency of $12 \mathrm{kHz}$ with $7.5 \mathrm{kV}_{p-p}$ of applied voltage and $4 \mathrm{slm}$ of helium flow rate. The distance between the nozzle of the Pyrex tube and the sample was fixed at 15 $\mathrm{mm}$. The bacteria were exposed to the DBD plasma jet for different time intervals (1, 3, 5, 10 and $15 \mathrm{~min})$. After treatment, all samples were incubated for $24 \mathrm{~h}$ at $37^{\circ} \mathrm{C}$. 


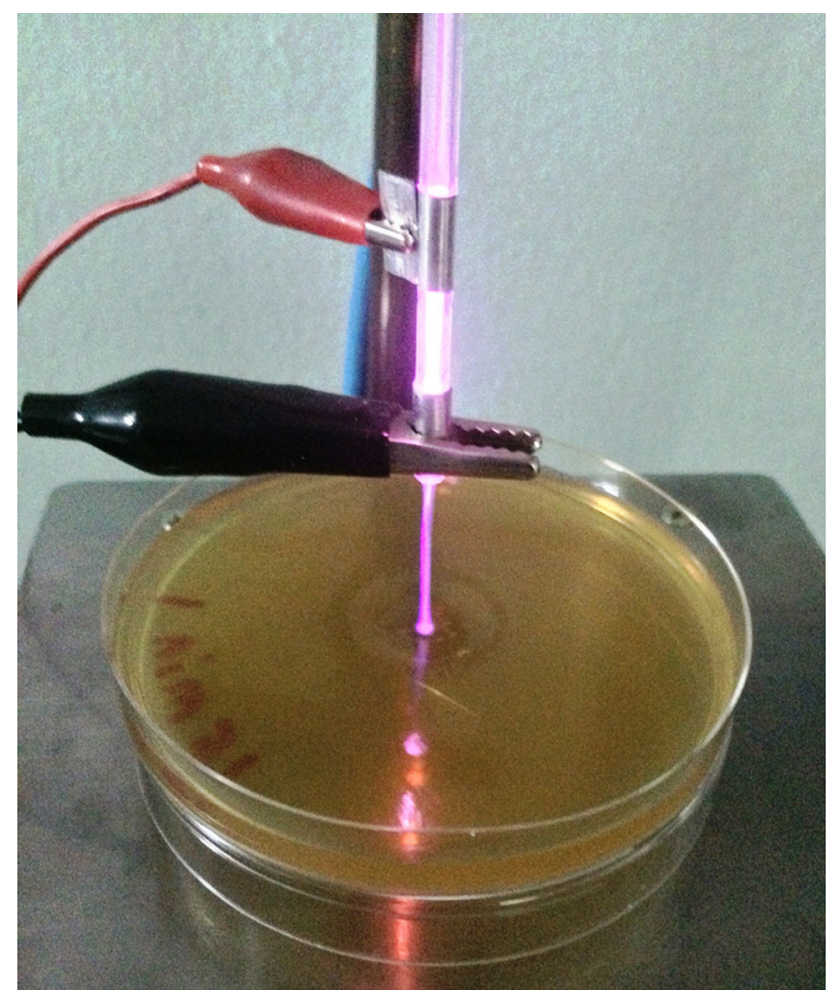

Fig. 2 Photograph of the DBD plasma jet interacting with Staphylococcus aureus bacteria

\section{Measuring the inhibition zones}

To determine the effect of plasma treatment on bacterial samples, the approximate diameter of inhibition zones which formed on agar was measured using Vernier calipers. To improve the measurements precision of irregular zones, advanced image software was used to calculate the diameter of the inhibition zones.

\section{Measuring the Reynold number}

The state of the helium flow is achieved by calculating the Reynolds number $\left(R_{n}\right)$, which describes the stability of flow such as the stable laminar flow and the turbulent flow [18]. The Reynolds number can be calculated by the following formula [19]:

$$
R_{n}=2.12 \times 10^{-2}\left(\frac{\rho}{\mu}\right) \times\left(\frac{Q}{r_{D}}\right),
$$

where $\rho$ is the fluid density, $\mu$ is the viscosity, $Q$ is the flow rate and $r_{\mathrm{D}}$ is the inner diameter of the tube.

\section{Results and discussion}

The typical waveforms of current discharge produced in the DBD plasma jet is shown in Fig. 3. The current in the first cycle increases rapidly with increased applied voltage, but decreases dramatically before the applied voltage reaches the peak value. This is attributed to the shielding effect (memory effect), which is caused by the accumulation of negative charge on the Pyrex tube [20]. This effect is a well-known mechanism of the DBD plasma which avoids arcing and makes the plasma plume harmless. Also, at higher voltage the values of the current pulses increase and their amplitude decreases. Further, the discharge current has many pulses for each cycle of the applied voltage which can be attributed to a glow-like discharge (multi pulse glow discharge) [21]. Therefore, the discharge current produced from the DBD plasma jet is considered a uniform breakdown [22].

Figure 4 shows the effect of helium flow rate on the length of the plasma plume with two values of applied voltage. As can be seen in this figure, the length of the plume rapidly increases with the gas flow rate from 1 to 4 slm. The plasma plume reached the maximum length of 44 $\mathrm{mm}$ when the applied voltage was $7.5 \mathrm{kV}_{p-p}$ and $41 \mathrm{~mm}$ when the applied voltage was $4.7 \mathrm{kV}_{p-p}$. This indicates that the effect of increased applied voltage leads to a slight increase in the length of the plasma plume because of the increase of electron mobility and electric field intensity [23].

If the gas flow rate increases over $4 \mathrm{slm}$, the length of the plasma plume decreases dramatically at both values of applied voltage. This is because of the effect of Reynolds number. If the $R_{n}$ is relatively small, such as $R_{n}<2000$, the flow is laminar. If it is large, i.e., $R_{n}>4000$, the flow is turbulent [24]. At $5 \mathrm{slm}$, the $R_{n}$ is 4527 , and this causes the

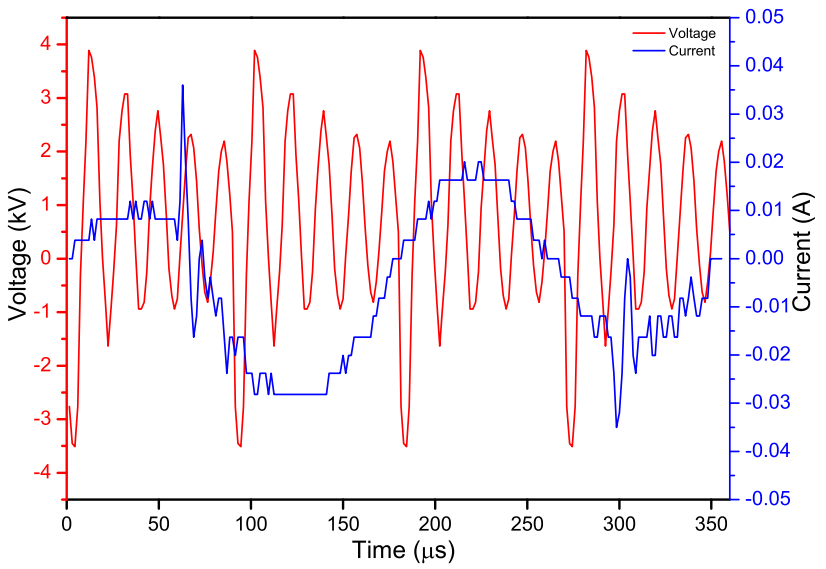

Fig. 3 Waveform of the applied voltage and discharge current under a helium flow rate of $4 \mathrm{slm}$ 


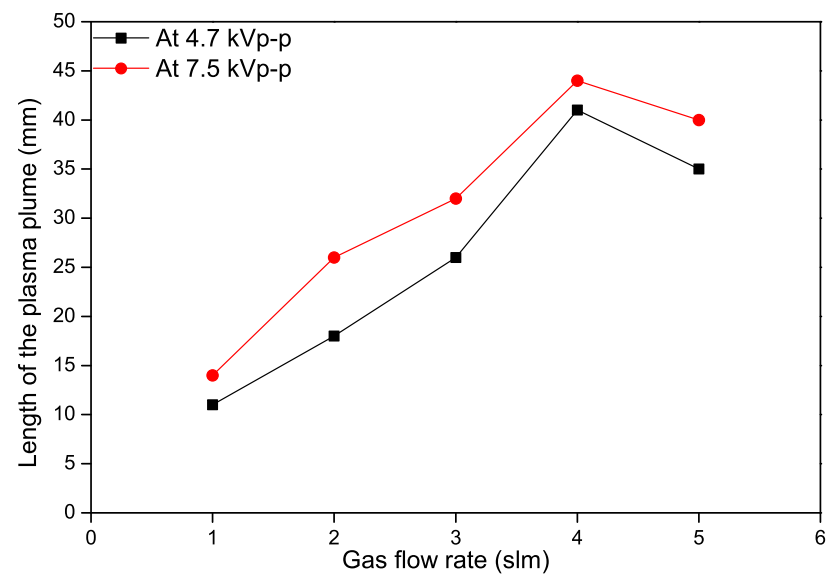

Fig. 4 Plasma plume length as a function of helium flow rate

flow rate to become turbulent and results in instabilities and deformations of the gas flow rate [25].

Figure 5 shows the gas temperature as a function of the irradiation time with various gas flow rates at the plasma conditions of $12 \mathrm{kHz}$ and $7.5 \mathrm{kV}_{p-p}$. As observed in this figure, the highest temperature reached $39{ }^{\circ} \mathrm{C}$ at $1.5 \mathrm{~min}$ with a gas flow rate of $2 \mathrm{slm}$ and the lowest temperature reached $29{ }^{\circ} \mathrm{C}$ at $0.5 \mathrm{~min}$ with a flow rate of $5 \mathrm{slm}$. This indicates that the gas temperature increased with irradiation time and decreased with gas flow rate. Further, the gas temperature at all flow rates reached thermal equilibrium after $1.5 \mathrm{~min}$ of plasma exposure and remained the same up to $15 \mathrm{~min}$.

The effect of the distance from plasma jet exit on the gas temperature is shown in Fig. 6. It is observed that the gas temperature at $4 \mathrm{slm}$ decreased from 38 to $34{ }^{\circ} \mathrm{C}$ and from 42 to $38.5^{\circ} \mathrm{C}$ at $2 \mathrm{slm}$ when the distance increased from 5 to $15 \mathrm{~mm}$. It is worth mentioning that the effect of reducing the distance between the plasma jet exit and the target has an important role in the inactivation efficiency of bacteria.

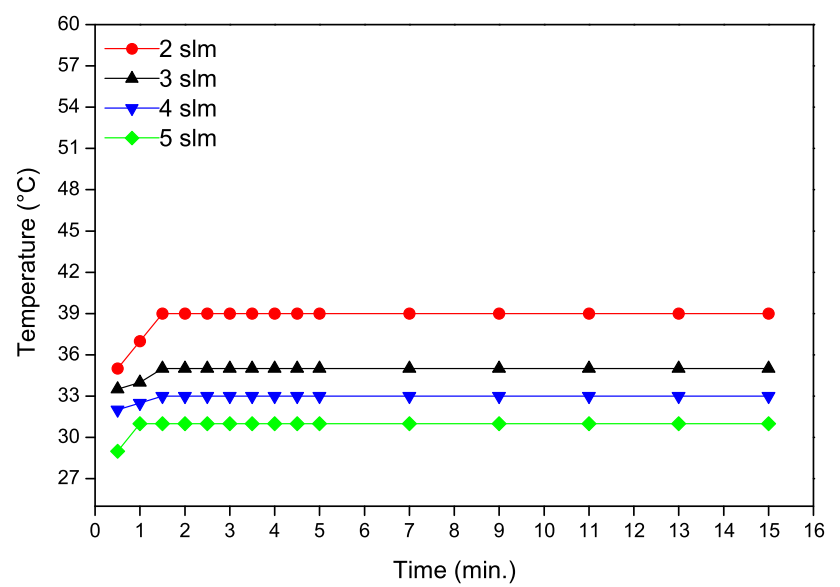

Fig. 5 Gas temperature as a function of the time for various helium flow rates

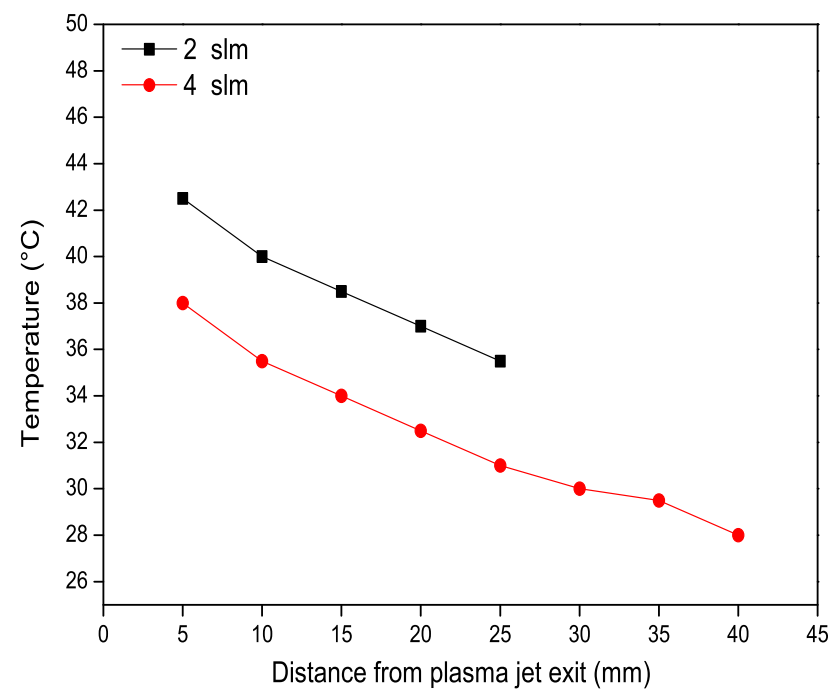

Fig. 6 Gas temperature as a function of the distance from the nozzle of the Pyrex tube

This is because the decrease in the distance leads to the generation of more active species, which play an important role in the inactivation process of bacteria. On the other hand, reducing the distance between the plasma jet exit and the target increases the temperature. Therefore the distance should be optimized so as not to exceed the plasma temperature above $43{ }^{\circ} \mathrm{C}$ [26].

The DBD plasma jet propagation to the surrounding air leads to interaction with air molecules, forming active species such as reactive oxygen and nitrogen species [27]. Figure 7 shows the spectral lines of the DBD plasma jet emitted in the UV-Vis regions. The band of excited molecular nitrogen is detected in the UV region at $357 \mathrm{~nm}$, while the ionized nitrogen can be found in the Vis region at $427 \mathrm{~nm}$. In addition, the spectral lines of ionic oxygen are detected in the UV-Vis region between 337 and $469 \mathrm{~nm}$. The spectral lines of hydrogen and atomic oxygen can be

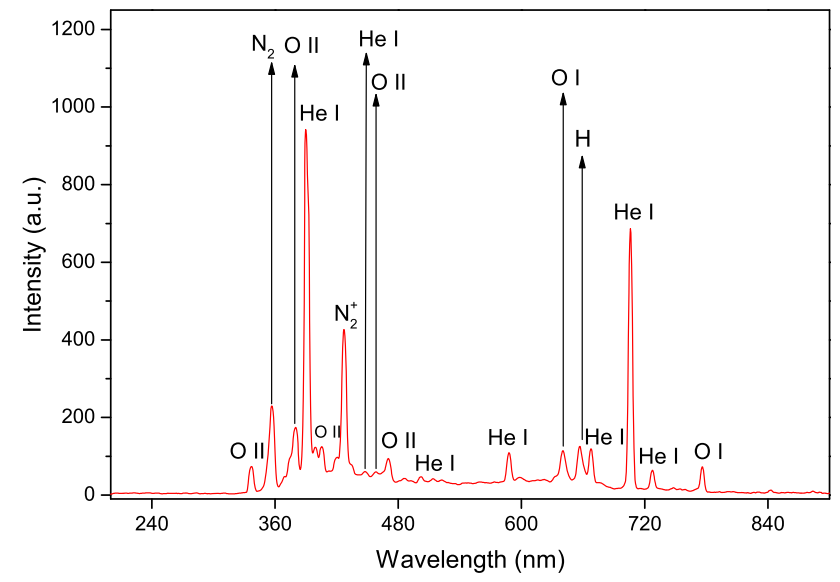

Fig. 7 Typical spectral lines of the DBD plasma jet 
found in the Vis regions at $656 \mathrm{~nm}$ for hydrogen, with 645.3 and $777 \mathrm{~nm}$ for atomic oxygen. Several spectral lines of atomic helium can be observed in UV-Vis regions between 388 and $728 \mathrm{~nm}$.

The spectral line intensities of the $\mathrm{N}_{2}^{+}, \mathrm{N}_{2}, \mathrm{H}, \mathrm{O}$ II and $\mathrm{O}$ I as a function of helium flow rate are shown in Fig. 8. As observed in this figure, increasing the helium flow rate leads to higher intensities of spectral lines. This is because the increase in gas flow rate results in a lower mole fraction of air which surrounds the plasma plume. The lower mole fraction of air can lead to higher local electron concentration. This explains the higher emission intensity from excited species [28, 29]. Some authors showed that the increase of gas flow rate is very significant to increase the amount of reactive oxygen and nitrogen species (RONS), which in turn contribute to cell death by damage of the DNA molecules [30].

Figure 9 shows the images of bacteria after treatment by DBD plasma jet for 3, 5 and $15 \mathrm{~min}$. It is observed that the inhibition zone diameter extends with increased plasma exposure time. Some authors have reported that the increase of plasma treatment time leads to increasing effectively the inactivation of microorganisms [31].

The diameter of the inhibition zones for $S$. aureus bacteria was determined and it is presented in Fig. 10 under different times of treatment. It is observed that the inhibition zone diameter exhibits a linear increase with plasma exposure time, and the inhibition zone diameter reached the maximum value at $53.37 \pm 0.8 \mathrm{~mm}$ under $15 \mathrm{~min}$ of plasma exposure.

Figure 11 shows the relationship of the survival amounts versus helium plasma jet treating times. The curve drops sharply in about $1 \mathrm{~min}$, which means the amounts of alive

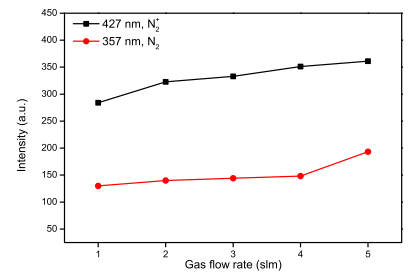

(a)

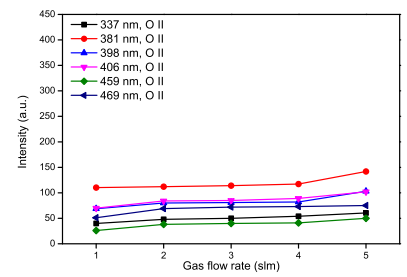

(c)

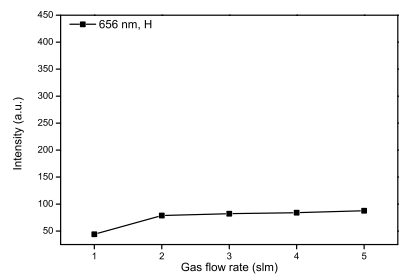

(b)

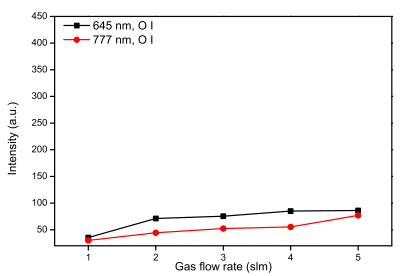

(d)
Fig. 8 Emission intensities of $\mathbf{a} \mathrm{N}_{2}^{+}$and $\mathrm{N}_{2}, \mathbf{b} \mathrm{H}, \mathbf{c} \mathrm{O}$ II and $\mathbf{d} \mathrm{O}$ II as a function of helium flow rate

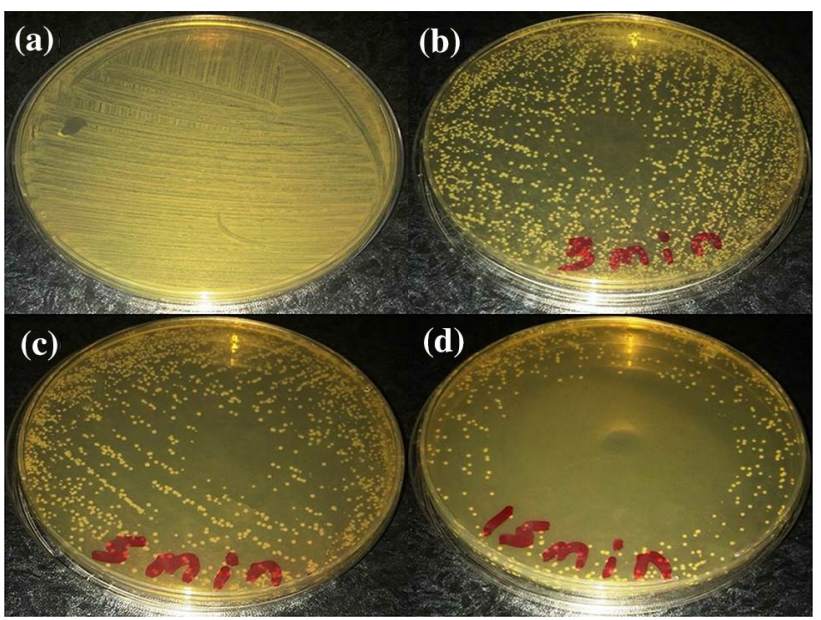

Fig. 9 Photographs of $S$. aureus samples after treatment by DBD plasma jet. a Sample not exposed to plasma. Sample exposed to bd plasma for 3,5 and $15 \mathrm{~min}$

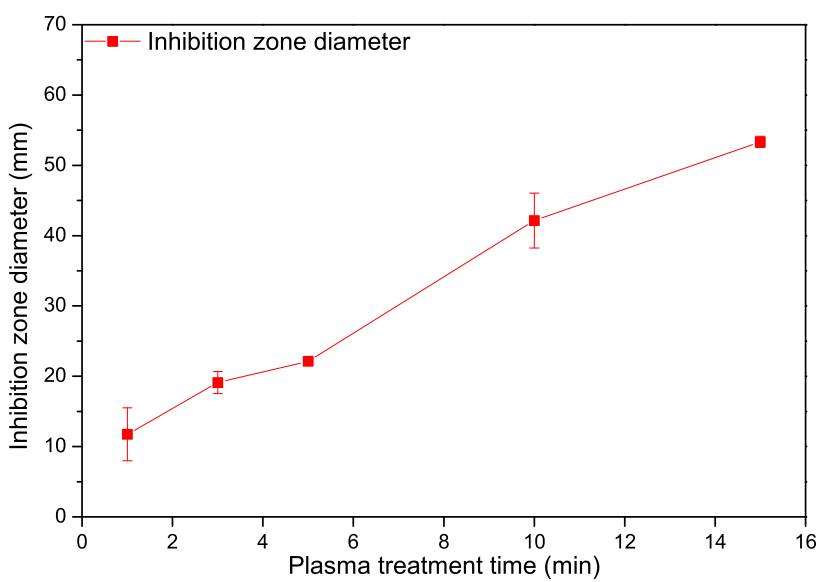

Fig. 10 Inhibition zone diameter of the $S$. aureus bacteria as a function of the plasma treatment time

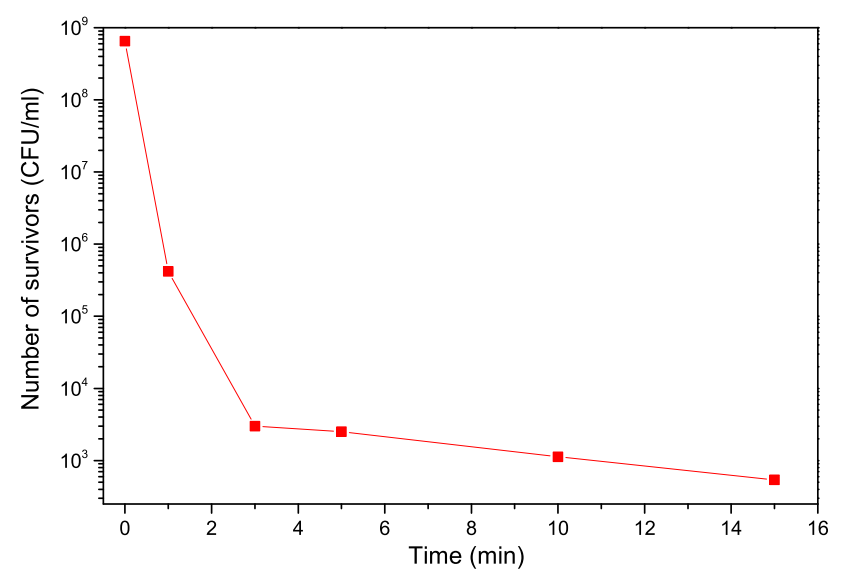

Fig. 11 Live cell amounts as a function of helium plasma exposure times 
cells decrease rapidly in the sample. After an extension of the treating time from 3 to $15 \mathrm{~min}$, the amounts of alive cells decrease relatively slowly. Therefore, it may be concluded that the killing rate is dependent on the treating times.

The mechanism of bacteria inactivation in plasma jet can occur by two known factors: physical and chemical factors. The physical factors include the heat, UV irradiation and charged particles, while the chemical factors include the active species.

At the operating plasma conditions of $12 \mathrm{kHz}, 7.5 \mathrm{kV}_{p-p}$ and $4 \mathrm{slm}$ used to treat the bacteria, the gas temperature reached $34{ }^{\circ} \mathrm{C}$. The effect of heat at this degree does not contribute to the process of bacteria inactivation. The charged particles produced from DBD plasma can be accumulated on the external surface of the cell membrane. These charges form an electrical force which can overcome the tensile strength of the cell membrane and cause its rupture. This process occurs if the plasma is directly exposed to the bacteria [32]. The concentration of charged particles decreases if the plasma indirectly exposes the bacteria (plasma afterglow) and this is due the quick recombination of the electrons and ions [33]. Therefore, it can be concluded that the charged particles play a secondary role in the process of bacteria inactivation, because all bacteria samples in this study were exposed to the plasma plume indirectly. Furthermore, the UV-C radiation intensity in the wavelength region of $180-280 \mathrm{~nm}$ may cause lethal harm to cells. Thus, the inactivation effect on microorganisms by ultraviolet irradiation in this range is mostly associated with DNA damage [34]. The intensities of the spectral lines in the range 180-280 $\mathrm{nm}$ were not observed when the plasma spectrum was diagnosed through optical emission spectroscopy (OES). Thus, it can be concluded that the UV irradiations do not play a major role in the process of bacteria inactivation.

As shown in Fig. 9, the number of colonies decreases significantly with increase in irradiation time, as a large number of colonies are killed even at the ends of the inhibition zone diameter. On the other hand, it is worth mentioning that the diameter of inhibition zone was always larger than the plasma plume diameter (equal to $1.5 \mathrm{~mm}$ ), which can be attributed to the fact that the inactivation occurred mostly due to the action of RONS. Studies have reported that reactive species in DBD plasma jet can contribute significantly to the inactivation process of bacteria [35]. Reactive species such as ROS generated by DBD plasma jet have damaging effects on cells, since they target proteins, DNA, cell wall and membrane [36]. For example, ROS, such as $\mathrm{O}$ and $\mathrm{O}_{3}$, can cause leakage of the cell membrane and induce DNA deterioration, which in turn causes the inactivation of bacteria [37].

\section{Conclusion}

In this study, the DBD non-thermal plasma jet was well designed to be an effective bactericidal when tested against $S$. aureus bacteria. With increased helium flow rate, the gas temperature decreased, while plasma plume length increased. According to OES, there are no peaks in the range $180-280 \mathrm{~nm}$. The absence of these peaks suggests that the UV radiation did not contribute to the inactivation process and therefore no lethal harm will be caused to the cells. The bacteria exposed to plasma showed an increase in the inhibition zone diameter with longer irradiation time. In addition, the diameter of inhibition zone was always larger than the plasma plume diameter, suggesting that the RONS played a major role in the inactivation process.

Acknowledgements The authors would like to thank the Environment and Water Directorate in the Ministry of Science and Technology of Iraq and the Department of Physics in the University of Kerbala, Iraq.

Open Access This article is distributed under the terms of the Creative Commons Attribution 4.0 International License (http://creative commons.org/licenses/by/4.0/), which permits unrestricted use, distribution, and reproduction in any medium, provided you give appropriate credit to the original author(s) and the source, provide a link to the Creative Commons license, and indicate if changes were made.

\section{References}

1. Colagar, A.H., Alavi, O., Motallebi, S., Sohbatzadeh, F.: Decontamination of Streptococcus pyogenes and Escherichia coli from solid surfaces by singlet and triplet atmospheric pressure plasma jet arrays. Arab. J. Sci. Eng. 41(6), 2139-2145 (2016)

2. Hijnen, W., Beerendonk, E., Medema, G.J.: Inactivation credit of UV radiation for viruses, bacteria and protozoan (oo) cysts in water: a review. Water Res. 40(1), 3-22 (2006)

3. Holyoak, G.R., Wang, S., Liu, Y., Bunch, T.D.: Toxic effects of ethylene oxide residues on bovine embryos in vitro. Toxicology 108(1-2), 33-38 (1996)

4. Yang, L., Chen, J., Gao, J.: Low temperature argon plasma sterilization effect on Pseudomonas aeruginosa and its mechanisms. J. Electrostatics 67(4), 646-651 (2009)

5. Matinzadeh, Z., Shahgoli, F., Abbasi, H., Ghoranneviss, M., Salem, M.K.: Degradation of bromophenol blue molecule during argon plasma jet irradiation. J. Theor. Appl. Phys. 11(2), 97-102 (2017)

6. Niedernhofer, L.J., Daniels, J.S., Rouzer, C.A., Greene, R.E., Marnett, L.J.: Malondialdehyde, a product of lipid peroxidation, is mutagenic in human cells. J. Biol. Chem. 278(33), 31426-31433 (2003)

7. Du, C., Liu, Y., Huang, Y., Li, Z., Men, R., Men, Y., Tang, J.: Qualitation and quantitation on microplasma jet for bacteria inactivation. Sci. Rep. 6, 18838 (2016)

8. Kuwahata, H., Kumazawa, E., Ohyama, R.-I., Itou, A.: Scanning electron microscopy image of Escherichia coli exposed with atmospheric-pressure plasma jet. e-J. Surf. Sci. Nanotechnol. 8, 74-76 (2010)

9. Kuwahata, H., Yamaguchi, T., Kojima, H., Kabayama, K.: Atmospheric-pressure plasma jet irradiation onto main 
components of the cell wall and membrane of Escherichia coli. e-J. Surf. Sci. Nanotechnol. 12, 400-403 (2014)

10. Xu, G.-M., Shi, X.-M., Cai, J.-F., Chen, S.-L., Li, P., Yao, C.-W., Chang, Z.-S., Zhang, G.-J.: Dual effects of atmospheric pressure plasma jet on skin wound healing of mice. Wound Repair Regen. 23(6), 878-884 (2015)

11. Schnabel, U., Polak, M., Winter, J., von Woedtke, T., Ehlbeck, J.: Plasma based technologies for reprocessing of medical devices, endoscopes and catheters. In: Plasma Science (ICOPS), 2012 Abstracts IEEE International Conference on, IEEE, pp. 3P-80, 2012

12. Lee, M., Kim, H., Kim, Y., Lee, W.Y., Baik, K.Y., Kaushik, N.K., Cho, G.: Blood coagulation with atmospheric-plasma jets. In: Plasma Science (ICOPS), 2012 Abstracts IEEE International Conference on, IEEE, pp. 2P-159, 2012

13. Moisan, M., Barbeau, J., Crevier, M.-C., Pelletier, J., Philip, N., Saoudi, B.: Plasma sterilization. Methods and mechanisms. Pure Appl. Chem. 74(3), 349-358 (2002)

14. Gaunt, L.F., Beggs, C.B., Georghiou, G.E.: Bactericidal action of the reactive species produced by gas-discharge nonthermal plasma at atmospheric pressure: a review. IEEE Trans. Plasma Sci. 34(4), 1257-1269 (2006)

15. Yasuda, H., Miura, T., Kurita, H., Takashima, K., Mizuno, A.: Biological evaluation of DNA damage in bacteriophages inactivated by atmospheric pressure cold plasma. Plasma Process. Polym. 7(3-4), 301-308 (2010)

16. Nishime, T., Borges, A., Koga-Ito, C., Machida, M., Hein, L., Kostov, K.: Non-thermal atmospheric pressure plasma jet applied to inactivation of different microorganisms. Surf. Coat. Technol. 312, 19-24 (2017)

17. Maisch, T., Shimizu, T., Li, Y.-F., Heinlin, J., Karrer, S., Morfill, G., Zimmermann, J.L.: Decolonisation of MRSA, S. aureus and E. coli by cold-atmospheric plasma using a porcine skin model in vitro. PloS One 7(4), e34610 (2012)

18. Jhin, S., Kim, Y., Lee, W.Y., Jin, D.J., Yu, H.-K., Kim, H., Koo, J.H., Cho, G.: Gas-flow rate and reynolds number in a tube of plasma jet device. In: Plasma Science (ICOPS), 2013 Abstracts IEEE International Conference on, IEEE, pp. 1, 2013

19. Jin, D.J., Uhm, H.S., Cho, G.: Influence of the gas-flow reynolds number on a plasma column in a glass tube. Phys. Plasmas 20(8), 083513 (2013)

20. Chiang, M., Wu, J.-Y., Li, Y., Wu, J., Chen, S., Chang, C.: Inactivation of E. coli and B. subtilis by a parallel-plate dielectric barrier discharge jet. Surf. Coat. Technol. 204(21), 3729-3737 (2010)

21. Radu, I., Bartnikas, R., Wertheimer, M.R.: Frequency and voltage dependence of glow and pseudoglow discharges in helium under atmospheric pressure. IEEE Trans. Plasma Sci. 31(6), 1363-1378 (2003)

22. De-Zhen, W.Y.-H.W.: Study on homogeneous multiple-pulse barrier discharge at atmospheric pressure. Acta Phys. Sin. 3, 050 (2005)

23. Zhang, R., Han, Q., Xia, Y., Li, S.: Plasma jet array treatment to improve the hydrophobicity of contaminated HTV silicone rubber. Plasma Sci. Technol. 19(10), 105505 (2017)
24. Mulley, R.: Flow of Industrial Fluids: Theory and Equations. CRC Press, Boca Raton (2004)

25. Mericam-Bourdet, N., Laroussi, M., Begum, A., Karakas, E.: Experimental investigations of plasma bullets. J. Phys. D Appl. Phys. 42(5), 055207 (2009)

26. Niemz, M.H.: Laser-Tissue Interactions: Fundamentals and Applications. Springer Science \& Business Media, Berlin (2013)

27. Kim, S.J., Chung, T.H., Joh, H.M., Cha, J.-H., Eom, I.S., Lee, H.J.: Characteristics of multiple plasma plumes and formation of bullets in an atmospheric-pressure plasma jet array. IEEE Trans. Plasma Sci. 43(3), 753-759 (2015)

28. Boselli, M., Colombo, V., Gherardi, M., Laurita, R., Liguori, A., Sanibondi, P., Simoncelli, E., Stancampiano, A.: Characterization of a cold atmospheric pressure plasma jet device driven by nanosecond voltage pulses. IEEE Trans. Plasma Sci. 43(3), 713-725 (2015)

29. Sakiyama, Y., Graves, D.B.: Neutral gas flow and ring-shaped emission profile in non-thermal RF-excited plasma needle discharge at atmospheric pressure. Plasma Sources Sci. Technol. 18(2), 025022 (2009)

30. Adhikari, E.R., Ptasinska, S.: Correlation between helium atmospheric pressure plasma jet (APPJ) variables and plasma induced dna damage. Eur. Phys. J. D 70(9), 180 (2016)

31. Baldanov, B., Semenov, A., Ranzhurov, T., Nikolaev, E., Gomboeva, S.: Action of plasma jets of a low-current spark discharge on microorganisms (Escherichia coli). Tech. Phys. 60(11), 1729-1731 (2015)

32. Mendis, D., Rosenberg, M., Azam, F.: A note on the possible electrostatic disruption of bacteria. IEEE Trans. Plasma Sci. 28(4), 1304-1306 (2000)

33. Laroussi, M., Mendis, D., Rosenberg, M.: Plasma interaction with microbes. New J. Phys. 5(1), 41 (2003)

34. Laroussi, M., Leipold, F.: Evaluation of the roles of reactive species, heat, and uv radiation in the inactivation of bacterial cells by air plasmas at atmospheric pressure. Int. J. Mass Spectrom. 233(1), 81-86 (2004)

35. Guimin, X., Guanjun, Z., Xingmin, S., Yue, M., Ning, W., Yuan, L.: Bacteria inactivation using DBD plasma jet in atmospheric pressure argon. Plasma Sci. Technol. 11(1), 83 (2009)

36. Mai-Prochnow, A., Murphy, A.B., McLean, K.M., Kong, M.G., Ostrikov, K.K.: Atmospheric pressure plasmas: infection control and bacterial responses. Int. J. Antimicrob. Agents 43(6), 508-517 (2014)

37. O'connor, N., Cahill, O., Daniels, S., Galvin, S., Humphreys, H.: Cold atmospheric pressure plasma and decontamination. Can it contribute to preventing hospital-acquired infections? J. Hosp. Infect. 88(2), 59-65 (2014)

\section{Publisher's Note}

Springer Nature remains neutral with regard to jurisdictional claims in published maps and institutional affiliations. 